\title{
(Pt/Co/Pt)/X MULTILAYER FILMS FOR MAGNETO-OPTIC MEDIA
}

\author{
G.A. BERTERO and R. SINCLAIR
}

Department of Materials Science and Engineering, Stanford University, Stanford, CA 94305-2205, USA

\begin{abstract}
We have sputter deposited (Pt/Co/Pt)/X multilayers (MLs) with the thickness of the Pt layers corresponding to one atomic monolayer, i.e., $2.3 \AA$, and $\mathrm{X}=\mathrm{Pd}, \mathrm{Ag}, \mathrm{Cu}, \mathrm{Ni}$. The Kerr rotation, $\Theta \mathrm{K}$, perpendicular anisotropy energy, $\mathrm{K}_{\perp}$, and magnetic coercivity, $\mathrm{Hc}$, all improve dramatically in the sputter-deposited $(\mathrm{Pt} / \mathrm{Co} / \mathrm{Pt}) / \mathrm{X}$ films over the corresponding $\mathrm{Co} / \mathrm{X}$ multilayers. In the $(\mathrm{Pt} / \mathrm{Co} / \mathrm{Pt}) / \mathrm{Pd}$ case the films show considerable property improvement over both $\mathrm{Co} / \mathrm{Pt}$ and $\mathrm{Co} / \mathrm{Pd}$ multilayers. When $\mathrm{X}=\mathrm{Ag}, \mathrm{Cu}, \mathrm{Ni}$ the increase in $\mathrm{K}_{\perp}$ is approximately ten-fold compared to $\mathrm{Co} / \mathrm{X}$ MLs and the Kerr rotation is high $\left(-0.15^{\circ}-0.3^{\circ}\right)$ and comparable to that of $\mathrm{Co} / \mathrm{Pt}$ films at short wavelengths.
\end{abstract}

KEYWORDS: MULTILAYERS, PERPENDICULAR ANISOTROPY, COERCIVITY, KERR ROTATION

\section{INTRODUCTION}

The perpendicular anisotropy, $\mathrm{K}_{\perp}$, in $\mathrm{Pt} / \mathrm{Co}$ multilayer thin films has been the subject of research by many investigators including the present authors [1-6]. Our findings indicate that $\mathrm{K}_{\perp}$. is extremely sensitive to the interface structure; sharper interfaces yielding the largest anisotropies $[7,8]$. Similarly, the Kerr rotation in these multilayers is interface structure dependent [8]. Near and above $3 \mathrm{eV}(400 \mathrm{~nm}), \Theta_{\mathrm{K}}$ is largely proportional to the magnetic polarization induced in the Pt layers. This is large for the first monolayer adjacent to the Co (of the order of $0.4 \mu_{\mathrm{B}}$ per $\mathrm{Pt}$ atom) but it decays quickly with distance from the interfaces. Thus, both $\mathrm{K} \perp$ and $\Theta_{\mathrm{K}}$ are properties with strong interfacial components which are both particularly large in the Co/Pt case.

This fact can be used to improve the properties of other $\mathrm{Co} / \mathrm{X}$ multilayers which do not originally display large perpendicular anisotropies or Kerr rotations. The approach we have taken is to deposit an atomic monolayer of $\mathrm{Pt}$ at the interfaces of $\mathrm{Co} / \mathrm{X}$ multilayers with $\mathrm{X}=\mathrm{Pd}, \mathrm{Cu}, \mathrm{Ag}$, and $\mathrm{Ni}$. The resulting multilayer structures, discussed in this work and referred to as $(\mathrm{Pt} / \mathrm{Co} / \mathrm{Pt}) / \mathrm{X}$ multilayers, display significantly improved properties [9]. For instance, the Kerr rotation, $\Theta_{K}$, perpendicular anisotropy energy, $\mathrm{K}_{1}$, and magnetic coercivity, $\mathrm{Hc}$, all increased dramatically in the sputter-deposited $(\mathrm{Pt} / \mathrm{Co} / \mathrm{Pt}) / \mathrm{X}$ films over the corresponding $\mathrm{Co} / \mathrm{X}$ multilayers. Furthermore, the spectral magnetooptic response was found to vary strongly with element $\mathrm{X}$ and in particular, $(\mathrm{Pt} / \mathrm{Co} / \mathrm{Pt}) / \mathrm{Ni}$ multilayers, show considerably larger Kerr rotations than the corresponding $\mathrm{Co} / \mathrm{Pt}$ films over a large range of wavelengths.

\section{EXPERIMENTAL}

All films were DC magnetron sputterdeposited at room temperature onto thermally oxidized silicon wafers in a UHV chamber (Fig. 1) with a base pressure of $3 \times 10^{-9}$ Torr. The substrate to target distance is of approximately $20 \mathrm{~cm}$ and the layering is carried out by the sequential opening and closing of computer controlled gun shutters.

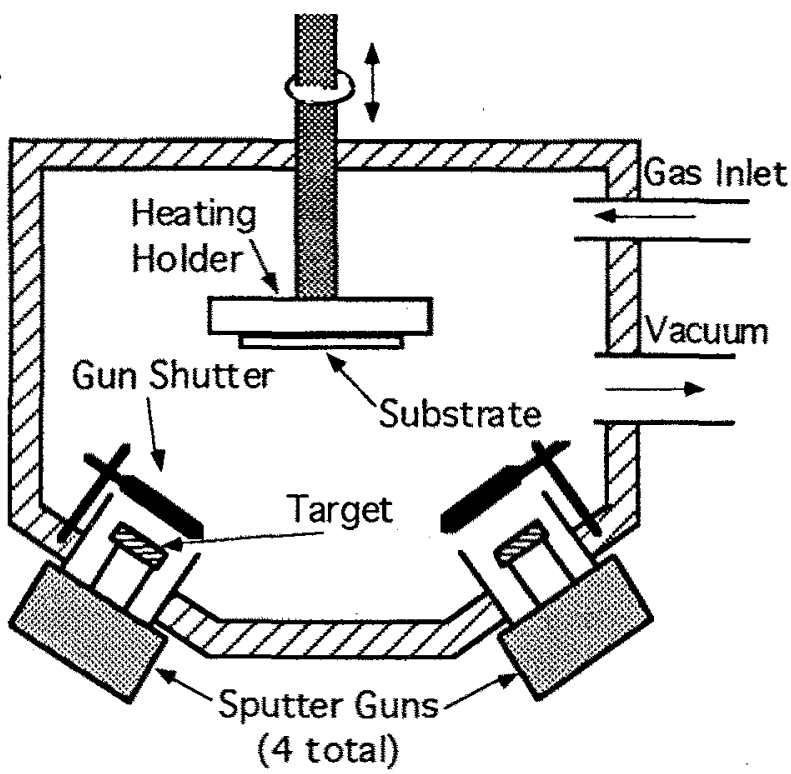

Figure 1: Schematic of the sputter deposition chamber,

Underlayer films composed of $100 \AA$ of $\mathrm{Pt}$ or $\mathrm{Pt} / \mathrm{Pd}$ bilayer films are deposited at $300^{\circ} \mathrm{C}$ to enhance the (111) crystallographic texture and control the grain size and structure; no capping layers were used for these films. Sputtering ambients were of $5.0 \mathrm{mTorr}$ 
Ar and Xe. Deposition rates were kept below 0.4 $\AA / \mathrm{s}$ for accurate thickness control. In the $(\mathrm{Pt} / \mathrm{Co} / \mathrm{Pt}) / \mathrm{X}$ films, the thickness of the Pt layers is of one atomic monolayer, the Co is $3.2 \AA$, and that of the element $X$ is approximately 5 to $8 \AA$ unless specified otherwise. All Kerr rotation hysteresis loops were obtained at $400 \mathrm{~nm}$ photon wavelength $(3.1 \mathrm{eV})$. Magnetic measurements were performed by conventional VSM and torque magnetometry techniques.

The films were characterized by transmission electron microscopy (TEM) observations in a Philips EM 430ST microscope with a point resolution of about $1.9 \AA$. Sample preparation for high resolution imaging (HREM) of cross-section specimens was performed utilizing the methods described elsewhere [10]. Care was exercised to avoid heating the films above $100^{\circ} \mathrm{C}$ when preparing the TEM specimens.

\section{RESULTS AND DISCUSSION}

Figure 2 shows Kerr rotation hysteresis loops from $\mathrm{Ar}$ - and $\mathrm{Xe}$-sputtered $(\mathrm{Pt} / \mathrm{Co} / \mathrm{Pt}) / \mathrm{Pd} \mathrm{MLs}$ deposited onto a (60 $\AA \mathrm{Pt} / 30 \AA \mathrm{Pd})$ underlayer film. The magnetic coercivity is extremely high in both cases and the Kerr rotation is similar to that of $\mathrm{Co} / \mathrm{Pt}$ MLs with comparable magnetic and non-magnetic $(\mathrm{Pt}+\mathrm{Pd})$ layer thicknesses. The perpendicular magnetic anisotropy in these $(\mathrm{Pt} / \mathrm{Co} / \mathrm{Pt}) / \mathrm{Pd}$ films has been found to be significantly higher $(33 \mathrm{Merg} / \mathrm{cc}$ Co) than that of corresponding Ar-sputtered $\mathrm{Co} / \mathrm{Pt}$ multilayers. This can be appreciated in the torque magnetometry results shown in Figure 3 for $\mathrm{Co} / \mathrm{Pt}$ and $(\mathrm{Pt} / \mathrm{Co} / \mathrm{Pt}) / \mathrm{Pd}$ films. The large anisotropy present in the $(\mathrm{Pt} / \mathrm{Co} / \mathrm{Pt}) / \mathrm{Pd}$ films gives room for the use of thicker Co layers, despite the larger demagnetizing energy contribution, yet displaying $100 \%$ remanence as is shown in the MO loop of Figure 4 from an Ar-sputtered multilayer film where the Co layer thickness is of $8.1 \AA$.

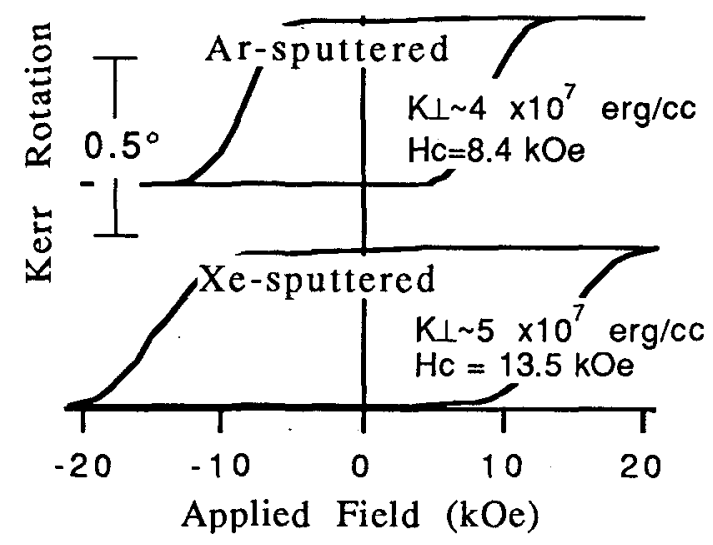

Figure 2: MO hysteresis loops from $(2.3 \AA \mathrm{Pt} / 3.2 \AA$ $\mathrm{Co} / 2.3 \AA \mathrm{Pt}) / 6 \AA \mathrm{Pd}$ MLs sputtered in $\mathrm{Ar}$ and Xe ambients.

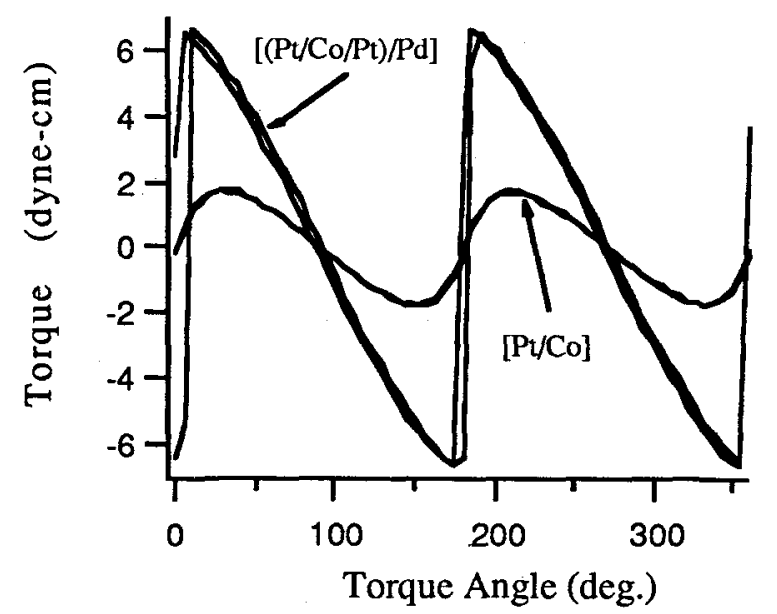

Figure 3: Torque magnetometry results from $\mathrm{Co} / \mathrm{Pt}$ and $(\mathrm{Pt} / \mathrm{Co} / \mathrm{Pt}) / \mathrm{Pd} \mathrm{MLs}$ Ar-sputtered at $5 \mathrm{mTorr}$ pressure. The Magnetic anisotropy energy, $\mathrm{K} \perp$, derived from these curves is of $7 \mathrm{Merg} / \mathrm{cc}(\mathrm{Co})$ for the $\mathrm{Co} / \mathrm{Pt}$ film and of 33 $\mathrm{Merg} / \mathrm{cc}(\mathrm{Co})$ for the $(\mathrm{Pt} / \mathrm{Co} / \mathrm{Pt}) / \mathrm{Pd}$ film. Happ $=20 \mathrm{kOe}$.

$(2.3 \AA \mathrm{Pt}, 8.1 \AA \mathrm{C} \text { co, } 2.3 \AA \mathrm{Pt}, 10.0 \AA \mathrm{Pd})_{12}$

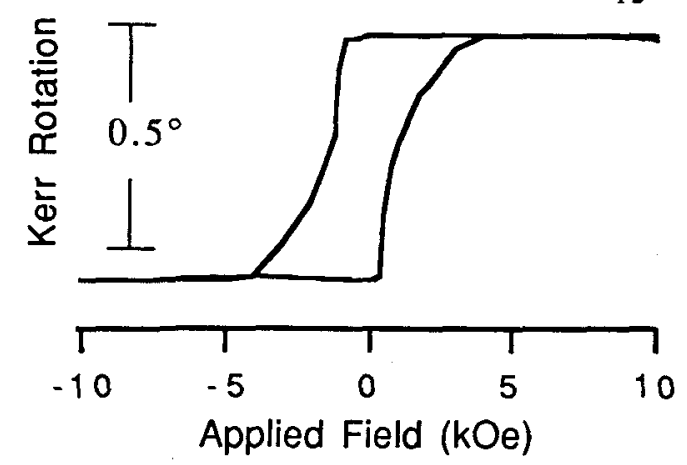

Figure 4: MO hysteresis loop from a $(\mathrm{Pt} / \mathrm{Co} / \mathrm{Pt}) / \mathrm{Pd}$ multilayer with the Co layer thickness of $8.1 \AA(\sim 4$ atomic monolayers), sputtered in $\mathrm{Ar}$ at 5 mTorr.

The large coercivity of the films shown in Figure 2 can be explained by the large grain separation observed in the TEM images combined with the large magnetic anisotropy. Similar multilayers deposited onto $100 \AA \mathrm{Pt}$ underlayers display equivalent $\mathrm{K}_{\perp}$ values while showing considerably less grain separation and coercivity [9]. Figure 5 shows high resolution TEM images of the cross section of one of the films of Fig.2. The grains can frequently be seen physically separated by a few Angstroms. Electron diffraction, shown in the inset, indicates that the texture is strongly (111) out of the plane as desired and similar to that found in $\mathrm{Co} / \mathrm{Pt}$ multilayers. HRTEM also indicates that the layers are coherent which is also confirmed by $\mathrm{x}$ ray diffraction from the presence of multiple high angle multilayer peaks. The nominally $2.3 \AA$ thick Pt layers (in darkest contrast) at either side of the nominally $3.1 \AA$ Co layers (lightest contrast) can 
clearly be seen. The thicker layers, showing intermediate gray contrast, correspond to the $9 \AA$ of Pd per period. This layering structure is remarkably similar to the idealized one and suggests that the intermixing is not extensive in the $\mathrm{Xe}$ sputtered film. In this regard, Ar-sputtered $\mathrm{Co} / \mathrm{Pt}$ multilayers are found to present considerably more intermixed layers resulting in smaller anisotropies (e.g. [7, 11]). The reason for this difference in intermixing is due at least in part by the effects of Ar backscattering from the heavy mass $\mathrm{Pt}$ target [12]. In the case of Xe-sputtering this effect is less serious since the heavier $\mathrm{Xe}^{+}$ion transfers its energy to the $\mathrm{Pt}$ with better efficiency and thus is less likely to backscatter with enough energy to cause damage on the growing film.
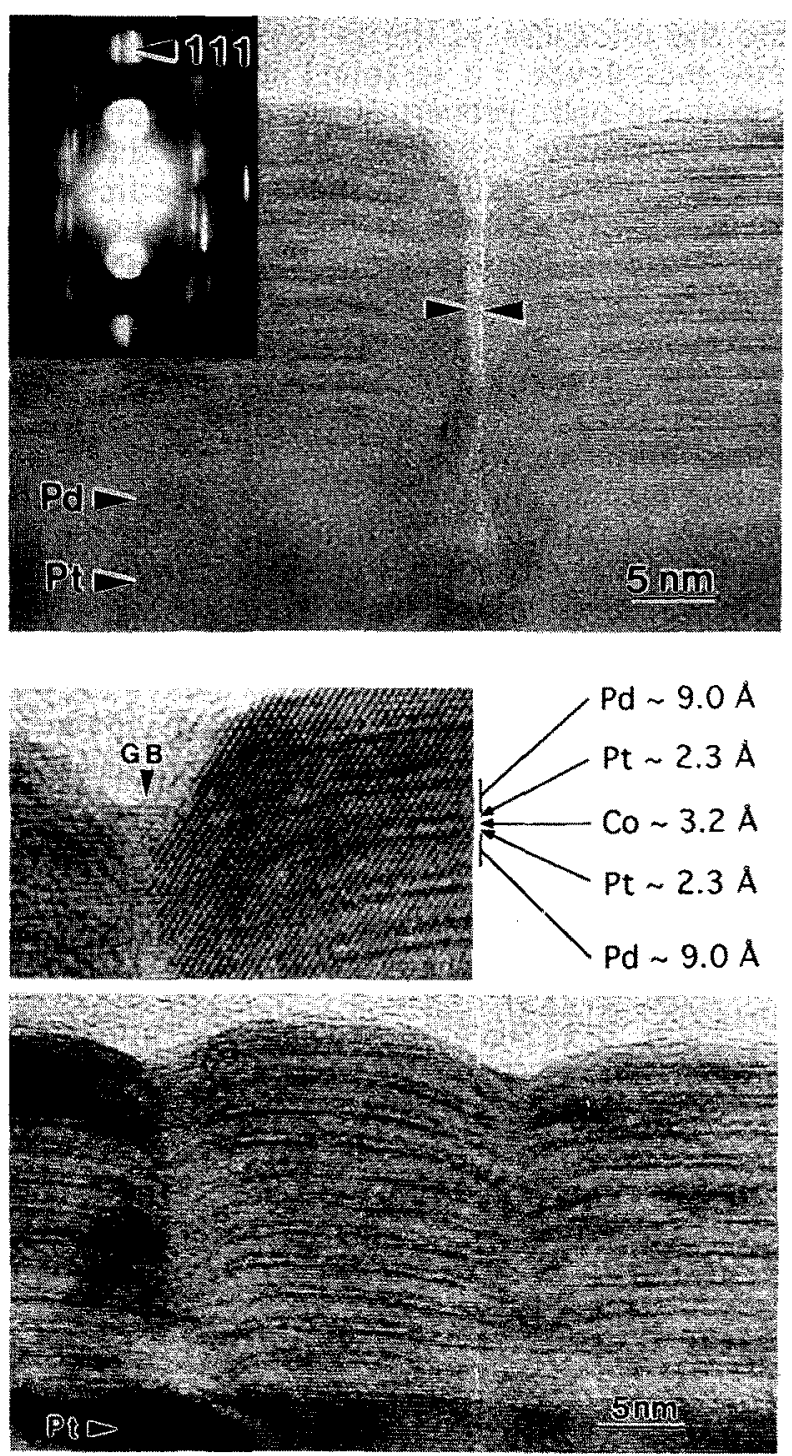

(a)

(b)

Figure 5: Cross-section HRTEM micrographs from $(\mathrm{Pt} / \mathrm{Co} / \mathrm{Pt}) / \mathrm{Pd}$ mutltilayers sputtered in Xe showing the grain boundary structure of a ML film deposited onto a $(60 \AA \mathrm{Pt}+30 \AA \mathrm{Pd})$ underlayer in (a) and the layer structure of a ML film deposited onto $100 \AA$ of $\mathrm{Pt}$ in (b). The inset in (a) shows the strong (111) texture present.
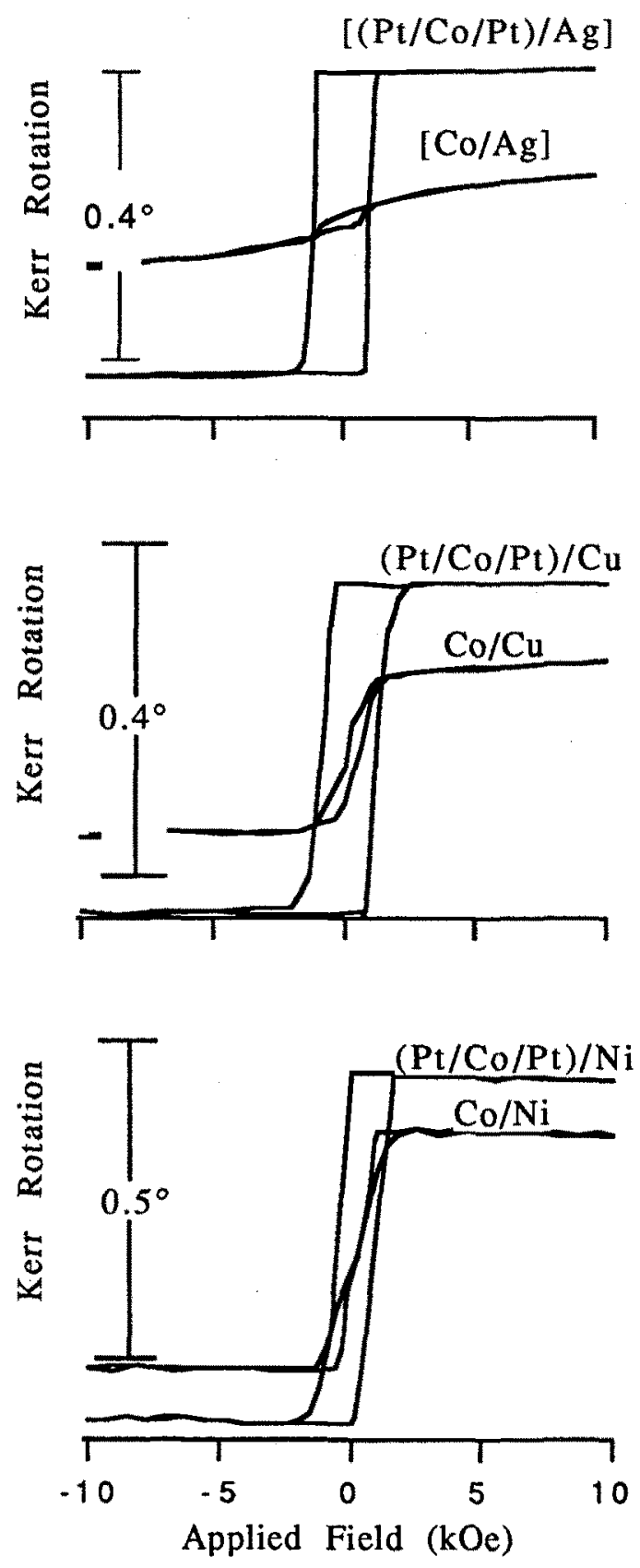

Figure 6: $\mathrm{MO}$ hysteresis loops from $(\mathrm{Pt} / \mathrm{Co} / \mathrm{Pt}) \mathrm{X}$ multilayers compared to their respective $\mathrm{Co} / \mathrm{X}$ multilayers. A large increase in anisotropy, coercivity and Kerr rotation takes place with the addition of the $\mathrm{Pt}$ atomic monolayers adjacent to the Co layers.

The increase in perpendicular anisotropy with the addition of the Pt atomic monolayers at the $\mathrm{Co} / \mathrm{Pd}$ interfaces is also present when a monolayer of $\mathrm{Pd}$ is deposited at the interfaces of Co/Pt films, i.e., $(\mathrm{Pd} / \mathrm{Co} / \mathrm{Pd}) / \mathrm{Pt}$ films. The additional structural anisotropy introduced into the multilayer structure by the extra $\mathrm{Pt}$ or $\mathrm{Pd}$ atomic monolayers adjacent to the Co layers, results in higher magnetic anisotropies because of the extra spin-orbit coupling originating at the added interface regions 
where the crystal symmetry is broken. Polarized spins are available in those regions because of the high polarizability of $\mathrm{Pt}$ and $\mathrm{Pd}$. In the absence of these extra, chemically distinct atomic monolayers, the orbital moments within the $\mathrm{Pd}$ or $\mathrm{Pt}$ spacer layers are necessarily compensated ("quenched") by the cubic symmetry of the Pt or Pd lattice and thus no extra contribution to $K_{1}$ from spin-orbit coupling can take place, in spite of the availability of polarized spins in these regions.

Substitution of Pd by other metals that allow for exchange coupling between Co layers also result in films with high perpendicular anisotropy. Figure 6 shows Kerr rotation hysteresis loops for $\mathrm{Co} / \mathrm{X}$ and $(\mathrm{Pt} / \mathrm{Co} / \mathrm{Pt}) / \mathrm{X}$ films with $\mathrm{X}=\mathrm{Ag}, \mathrm{Cu}$, and $\mathrm{Ni}$. A large increase in all the relevant magnetic and magnetooptical properties can be seen to take place with the addition of the thin atomic monolayer of $\mathrm{Pt}$ at the interfaces. The perpendicular anisotropy energy is seen to increase, as expected, as much as eight to ten-fold. As a consequence of this, the magnetic remanence (and thus the loop squareness) is basically $100 \%$ in all the $(\mathrm{Pt} / \mathrm{Co} / \mathrm{Pt}) / \mathrm{X}$ films.

The dependence of $\Theta_{K}$ with photon energy for these films is shown in Figure 7. Marked differences in the magneto-optical spectral response exist between them. However, all films, except $X=\mathrm{Ni}$, show behavior characteristic of $\mathrm{Co} / \mathrm{Pt}$ multilayers at short wavelengths. This indicates that the overall magneto-optic response is dominated by the magneto-optic activity of the Pt. The Kerr rotation displayed by the $(\mathrm{Pt} / \mathrm{Co} / \mathrm{Pt}) / \mathrm{Ni}$ film is relatively large throughout the entire spectrum. In particular, the large peak near $1.5 \mathrm{eV}$ is unmatched in the other systems and the Kerr rotation is everywhere significantly larger than that found in equivalent period Pt/Co multilayer films.

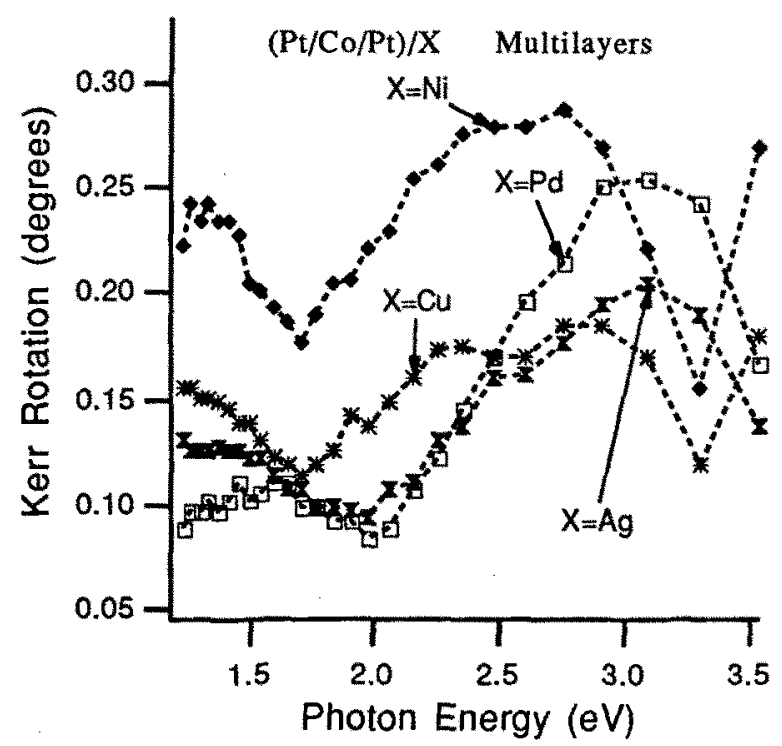

Figure 7: Kerr rotation spectra from $(\mathrm{Pt} / \mathrm{Co} / \mathrm{Pt}) / \mathrm{X}$ multilayers. The Kerr rotation from the $\mathrm{MLs}$ with $\mathrm{X}=\mathrm{Ni}$ is particularly high over an extended range of wavelengths.
Finally, the use of metallic underlayer films in this work, provide a way to control the texture and grain structure in order to make valid comparisons between films sputtered in $\mathrm{Ar}$ and Xe while keeping other structural variables the same. In a real application these multilayers can be deposited without underlayers. This is particularly true since most fcc and hcp metals such as Pt, Pd, and $\mathrm{Co}$, for example, have a strong tendency to grow preferentially along close packed plane normals.

\section{SUMMARY AND CONCLUSIONS}

Large anisotropies and very square hysteresis loops were observed in $(\mathrm{Pt} / \mathrm{Co} / \mathrm{Pt}) / \mathrm{X}$ films where the thickness of the Pt layer is of just one atomic monolayer. It is found that the magnetic and magneto-optic properties are dominated by the $\mathrm{Co} / \mathrm{Pt}$ interfaces and that the $\mathrm{Pt} / \mathrm{X}$ interfaces contribute additionally to these properties. In particular $(\mathrm{Pt} / \mathrm{Co} / \mathrm{Pt}) / \mathrm{Pd}$ films show the largest perpendicular anisotropies and $(\mathrm{Pt} / \mathrm{Co} / \mathrm{Pt}) / \mathrm{Ni}$ films present the largest Kerr rotations over a wide range of wavelengths. The relatively large magnetization of the latter, combined with its square out-of-plane hysteresis loop, makes it attractive not only as magneto-optic media but also as perpendicular recording media. Similarly, the large perpendicular anisotropy in $(\mathrm{Pt} / \mathrm{Co} / \mathrm{Pt}) / \mathrm{Pd}$ films allows for the use of thicker Co layers, with a corresponding increase in the total moments, yet maintaining $100 \%$ remanence.

\section{REFERENCES}

[1] P.F. Carcia, J. Appl. Phys. 63 (1988) 5066.

[2] H.J.G. Draaisma, W.J.M. d. Jonge and F.J.A. d. Broeder, J. Magn. Magn. Mater. 66 (1987) 351.

[3] E.R. Moog, J. Zak and S. D. Bader, J. Appl. Phys. 69 (1991) 4559.

[4] W.B. Zeper and F.J.A.M. Greidanus, IEEE Trans. on Mag. 25 (1989) 3764.

[5] W.B. Zeper, F.J.A.M. Greidanus, P. F. Carcia and C.R. Fincher, J. Appl. Phys. 65 (1989) 4971.

[6] R.H. Victora and J.M. MacLaren, J. Appl, Phys. 73 (1993) 6415.

[7] G.A. Bertero and R. Sinclair, J. Magn. Magn. Mater. 134 (1994) 173.

[8] G.A. Bertero and R. Sinclair, MRS Symp. Proc. 343 (1994) (in press).

[9] G.A. Bertero and R. Sinclair, Appl. Phys. Lett. 64 (1994) 3337.

[10] J.C. Bravman and R. Sinclair, J. Electron Microsc. Tech. 1 (1984) 52.

[11] P.F. Carcia, Z.G. Li and W.B. Zeper, J. Magn. Magn. Mater. 121 (1993) 452.

[12] P.F. Carcia, S.I. Shah and W.B. Zeper, Appl. Phys. Lett. 56 (1990) 2345. 